\title{
Dynamic effects of vehicles on the elements of bridge structures due to deformation of the approach slabs
}

\author{
Denis Razuvaev ${ }^{1, *}$, Michael Chakhlov ${ }^{1}$, and Roman Pechenkin ${ }^{1}$ \\ ${ }^{1}$ Siberian Transport University, Dusi Kovalchuk Str., 191, Novosibirsk, 630049, Russia
}

\begin{abstract}
As part of the study, a field experiment was conducted, the results of which were used to evaluate the dynamic effects of vehicles on the elements of bridge structures due to deformations of the approach slabs. Drawdowns of the pavement at the interfaces of artificial structures with approaching embankments lead to the development of additional dynamic transport impacts, which give them accelerations reaching 1.8 $\mathrm{m} / \mathrm{s}^{2}$ (for the studied objects). Taking into account a detailed survey of the places of interfacing bridges with approaching embankments, there has been proposed a method for eliminating the causes and consequences of the deflection of approaching slabs without disassembling existing structures. The method is based on the injection way of filling voids and fixing soils. A method of eliminating the causes and effects of deflection of approaching slabs without disassembling existing structures, based on the injection method of filling voids and fixing soils, ensuring evenness on the site by milling the coating with the laying of the leveling layer.
\end{abstract}

\section{Introduction}

Experience in the operation of roads shows that characteristic areas for deformation occurrences that directly affect the reduction of the coating flatness, and often lead to its destruction, are places where the artificial structures are connected with the approaching embankments [1]. Mates are important elements of roads, designed to ensure a smooth transition from a relatively pliable subgrade to a rigid support and the superstructure of an artificial structure [1].

Such deformations are caused by a whole complex of objective and subjective factors associated primarily with insufficient compaction of soils during the construction of the approach embankment and their excessive moisture during the subsequent operation of highways $[2,11]$. This type of deformation manifests itself, as a rule, in the form of local subsidence, which captures the interface zone [1]. The problem is exacerbated by the operation of roads in cold regions [3].

The fundamental role of highways is to provide high consumer properties, namely: continuous, convenient and safe movement of vehicles at a set speed, permissible

\footnotetext{
* Corresponding author: razdenis@mail.ru
} 
dimensions and loads during the standard service lifetime. The deterioration of the evenness of the coating in the areas of intersection of approaching embankments with bridges leads not only to a decrease in such consumer properties of roads as safety, comfort and speed, but also contributes to the development of additional dynamic traffic impacts on road structures.

Dynamic impacts that occur when a vehicle hits a plot with a local drawdown contribute to the further increase in residual deformations of the approaching slab, and may also lead to additional loads not taken into account when designing the end supports of the artificial structure, and as a result, reduce the reliability and lifetime of the structure. Frequent detection of subsidence of coatings in the areas of junction of suitable embankments with bridges, and in some cases roll of terminal supports, mainly of pile or column type, with a single row arrangement, indicates the relevance of the indicated problem.

The aim of the work is a quantitative assessment of the dynamic impact of vehicles on sections of operated bridges with subsidence of approaching slabs and the development of a technical solution to eliminate them.

\section{Research methods}

The studies were conducted on the section of the existing federal-level general use road "Northern Bypass of Novosibirsk (R-254)". Five reinforced concrete bridges have been designated as objects of study. In general, all bridges have a similar construction: the beams of the superstructure are combined into a temperature-continuous lash, foundations and intermediate supports are made in the form of pillars with a single row arrangement, and transitional reinforced concrete slabs are used as an interface to the approaching mounds.

During a reconnaissance survey and a visual inspection at all bridges, characteristic deformations at the junction of bridges with approach embankments were recorded. Deformations, as a rule, occur in the form of local subsidence and transverse cracks of the coating (Fig. 1). Deformations manifest themselves directly at a distance of 100 to $300 \mathrm{~mm}$ in front of the comb-like transitional plates of the expansion joint on the side of the approach slab.

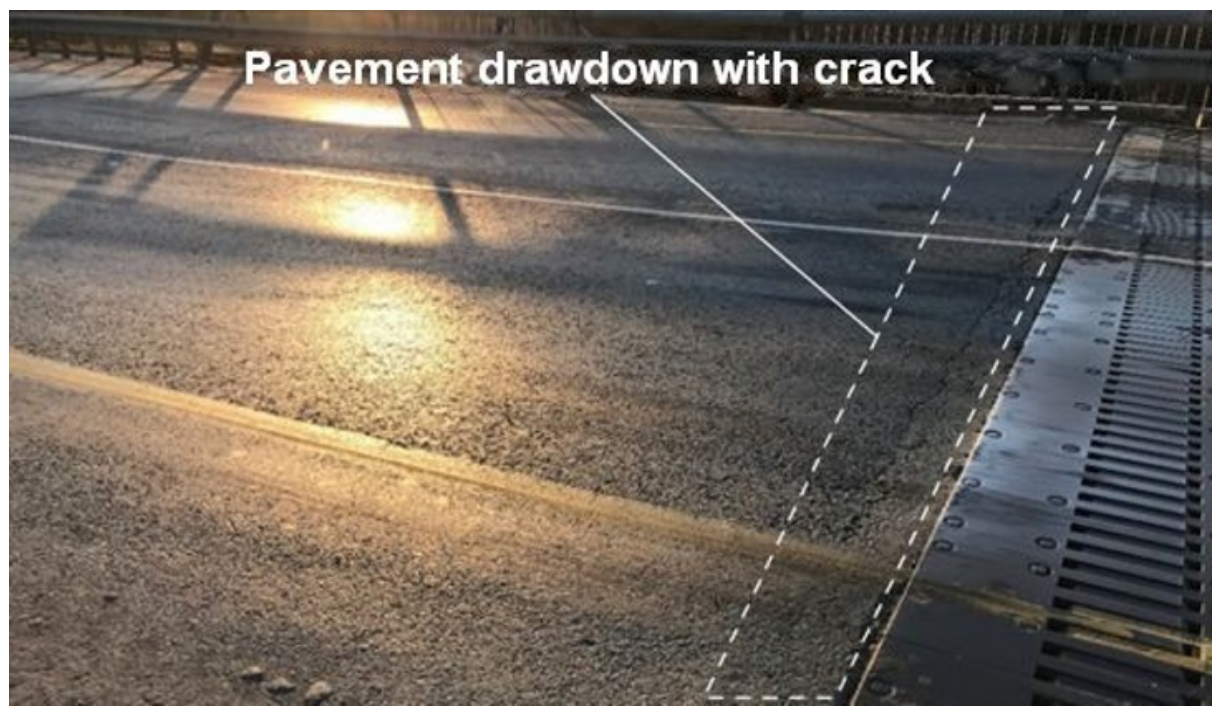

Fig. 1. Deformations of coating at interface with approaching embankment. 
Studies of the dynamics of transport effects in areas with subsidence of approaching slabs were carried out using three-axis accelerometers, the signal from which was recorded by a complex measuring microprocessor high-speed "Dynamics-3" (registered in the State Register of Measuring Instruments No. 66938-17) [4, 5, 6]. The vibration accelerations were measured with a sampling frequency of $32 \mathrm{kHz}$, the price of the smallest discharge of an analog-digital converter $0.0032 \mathrm{~m} / \mathrm{s}^{2}$ and a dynamic range from -13 to $+13 \mathrm{~m} / \mathrm{s}^{2}$.

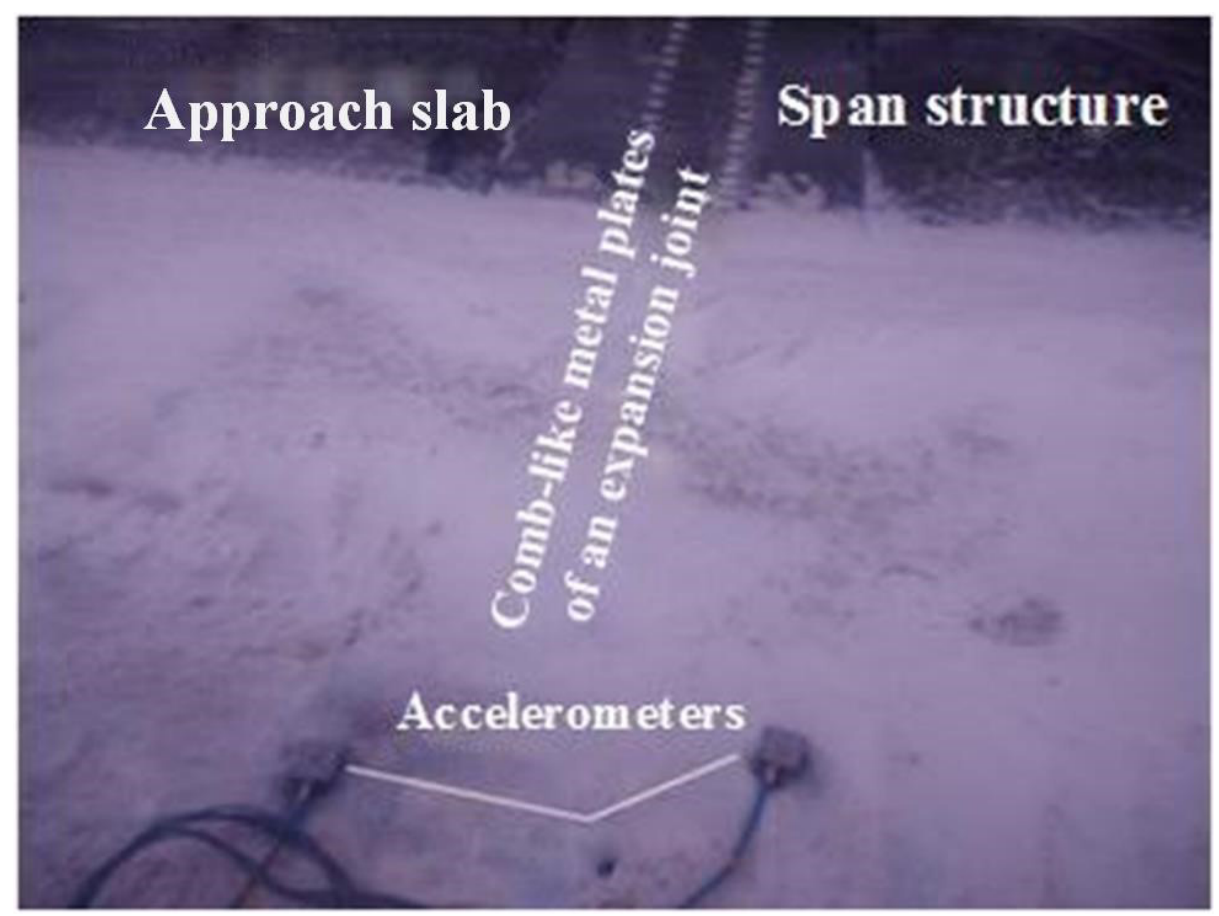

Fig. 2. Measuring complex "Dynamics-3".

Accelerometers installed in a dustproof, waterproof cases were attached to the comblike plates of the expansion joint (Fig. 3 and 4) above the backwall and above the span structure, respectively, using magnetic holders. Accelerometers provided registration of the three components of vibration accelerations $a_{x}, a_{y}, a_{z}$ (Fig. 3). The control of acceleration of the bridge structure elements was carried out in the monitoring mode under operating conditions when the vehicles were moving in a flow with speed limit of $60-80 \mathrm{~km} / \mathrm{h}$ set on this section. 


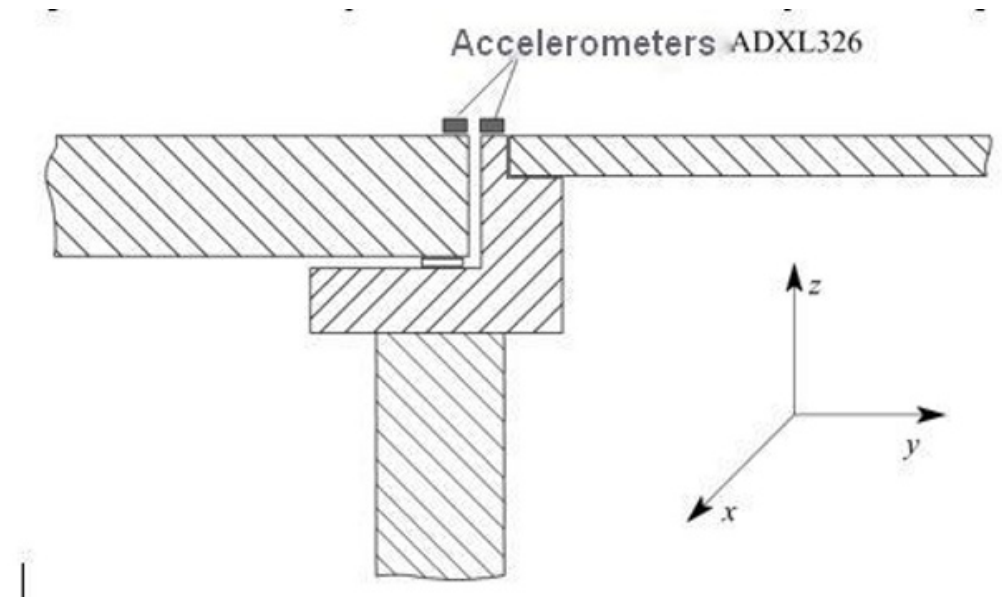

Fig. 3. Installation of accelerometers on the beam and bridge structure support.

\section{Research results}

When vehicles move along a bridge structure, the signals of accelerometers register pulsed oscillations [7, 8], a characteristic view of which is shown in Fig. 4. The time between pulses is about $0.1-0.2 \mathrm{~s}$, which corresponds to inter-axle dimensions for heavy vehicles $(1.8-2.5) \mathrm{m}$. The pulses have the characteristic form of damped harmonic oscillations with a duration from 0.1 to $0,2 \mathrm{~s}$ (Fig. 5). The significant duration of the oscillations leads to the imposition of a subsequent pulse on the damped oscillations of the previous one (Fig. 5). In this case, registered accelerations may increase or decrease due to interference phenomena. In Figure 5, two dynamic effects are observed at 0.17 and at $0.27 \mathrm{~s}$. The acceleration caused by the second exposure is three times less than the first.

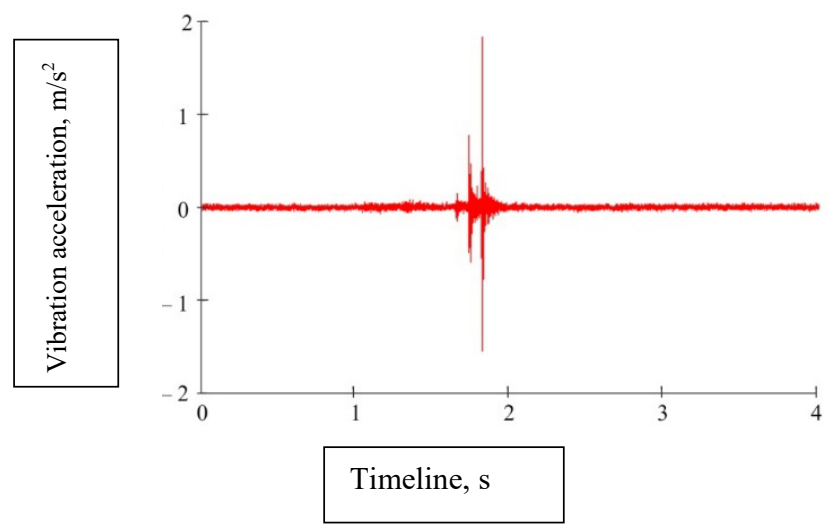

Fig. 4. Dependence of acceleration at accelerometers on time when driving vehicles. 


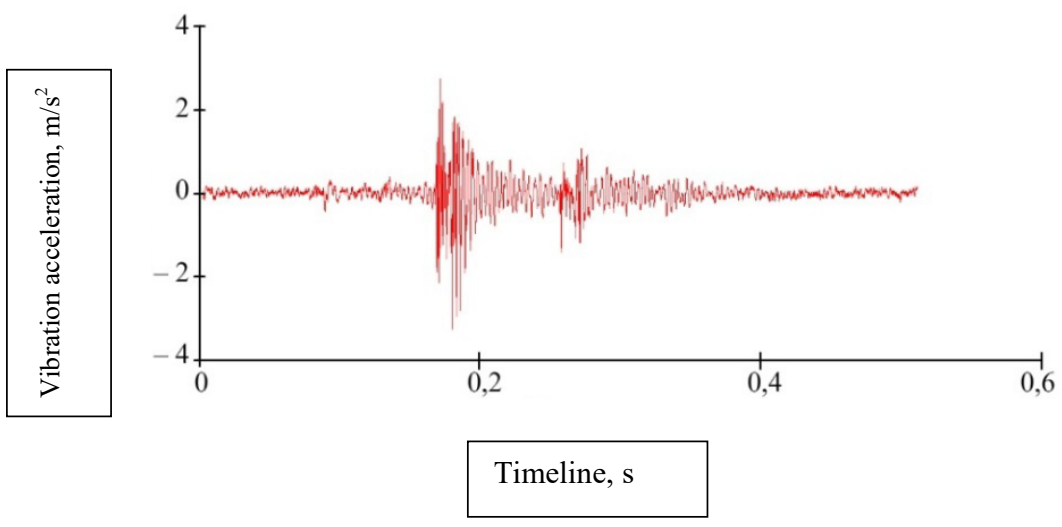

Fig. 5. Dependence of acceleration at accelerometers on time.

The spectrum of the recorded signals is broadband in the frequency range from $5 \mathrm{~Hz}$ to $4 \mathrm{kHz}$ (Fig. 6). In the spectrum, maxima are distinguished, exceeding the average amplitude level by 2-4 times. In Figure 6, the maximum value of the oscillation amplitude is observed at a frequency of $300 \mathrm{~Hz}$. The patterns of manifestation of global maxima in the spectrum of oscillations were not found, their frequency and amplitude are random in nature, caused by the superposition of oscillations from two or more sources.

The spectral density (Fig. 6) allows moving from an estimate of accelerations to displacements under the dynamic impacts of vehicles. In the model of a harmonic signal from time, the displacements are associated with accelerations:

$$
\Delta y=a_{\mathrm{fy}} \cdot(2 \cdot \pi \cdot f)^{-2}
$$

where afy is the spectral amplitude of vibration acceleration ay at the frequency $f$. The maximum amplitude of vibration displacement is observed in the low-frequency spectrum from 4 to $15 \mathrm{~Hz}$ and ranges from 0.5 to $1 \mathrm{~mm}$.
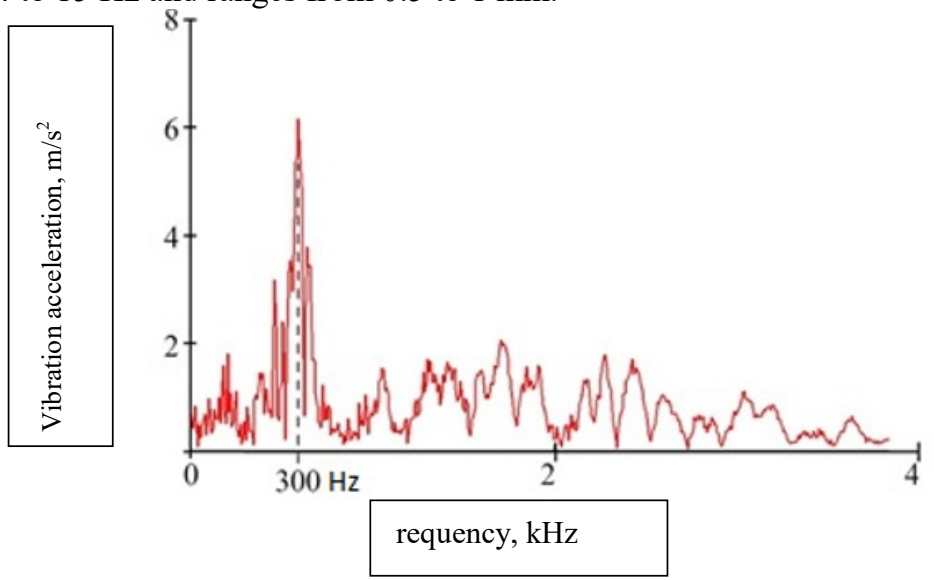

Fig. 6. Spectrum of vibration acceleration. 
The minimum accelerations on the bridge support are fixed in the transverse ax and vertical az directions, the amplitude values of the accelerations do not exceed 0.45 and 0.59 $\mathrm{m} / \mathrm{s} 2$, respectively. The greatest accelerations on the support are observed in the longitudinal direction ay. During the test, the amplitudes of accelerations from 0.5 to 2.6 $\mathrm{m} / \mathrm{s} 2$ were recorded (see Fig. 7). According to experimental data, statistical parameters of accelerations were calculated: the average value of $0.83 \mathrm{~m} / \mathrm{s} 2$, and the standard deviation $0.37 \mathrm{~m} / \mathrm{s} 2$. With a significance level of $5 \%$, acceleration may exceed $1.8 \mathrm{~m} / \mathrm{s} 2$ in operation. The average component acceleration ratio is az / ay $=0.53$ and, therefore, the total acceleration vector is directed at an angle of $26^{\circ}$ to the longitudinal axis of the bridge (Fig. 7).

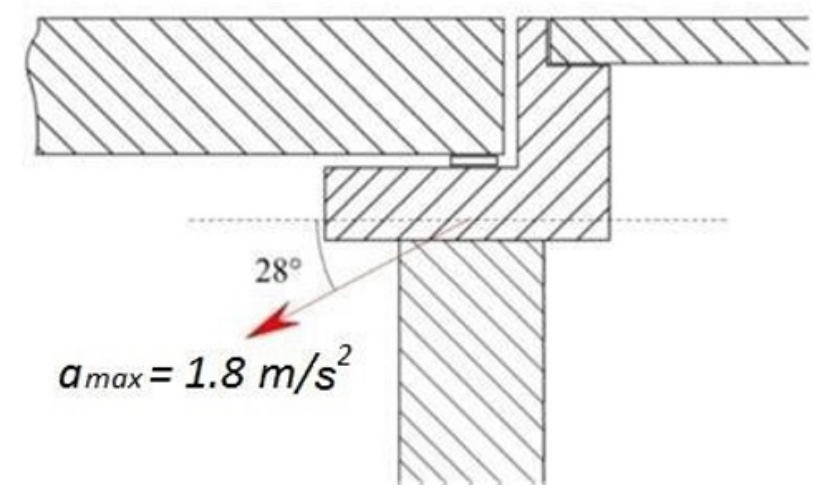

Fig. 7. Direction and absolute value of the resultant acceleration acting on the bridge support.

\section{Discussion of results}

Changing the profile of the roadway significantly affects the parameters of the dynamic interaction of vehicles with the bridge structure. During operation, the bridge support experiences short-term impacts, which give it additional acceleration, reaching $1.8 \mathrm{~m} / \mathrm{s} 2$.

In the static setting, the support operates in the field of gravity and the weight of the support is determined by the acceleration of gravity, equal to $9.8 \mathrm{~m} / \mathrm{s} 2$. Moreover, in the conditions of dynamic impact of vehicles, additional dynamic forces act on the support due to the acceleration of $1.8 \mathrm{~m} / \mathrm{s}^{2}$. Consequently, the dynamic coefficient determined by the ratio of the total acceleration to the acceleration of gravity is 1.2 .

The field studies allowed identifying and assessing the dynamic effects that occur when vehicles hit the deformed transitional areas from approaching embankments to bridges. Obviously, the effects of such a magnitude may further increase the residual deformations of the approach slab, and may also lead to additional loads not considered in the design of the end supports of the artificial structure, and as a result, reduce the reliability and service lifetime of structures. The rate of development of such deformations depends on a number of factors, the main of which are: the intensity and speed of traffic, the composition of the traffic flow, the design of the interface, as well as the initial value of the subsidence.

In order to develop a technical solution to eliminate and prevent further progress of deformations, an examination of the considered transition areas was carried out in order to establish their actual design and condition. 


\section{Engineering survey of transition sites}

As part of the engineering survey of the structures of transition sections, wells were drilled from the roadway through asphalt concrete pavement, concrete base and reinforced concrete approaching slab.

Drilling points were assigned along the axis of the lane in the places of manifestation of the greatest deformations in close proximity to the deformation seam (Fig. 8) for each bridge junction.

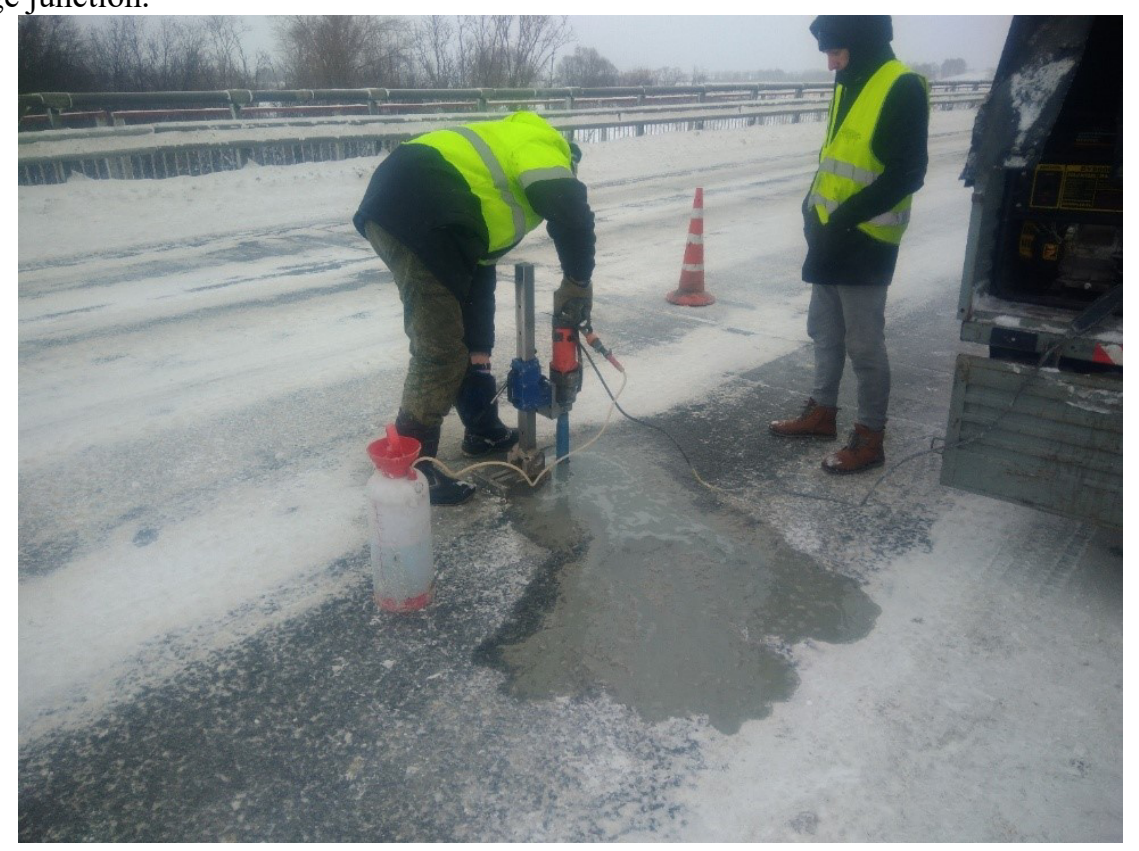

Fig. 8. Drilling a well along the lane axis.

After penetration of dense pavement materials, control measurements of the extracted core and depth were made. Road pavement in the field of coring is represented by a threelayer structure (asphalt concrete, concrete, approaching reinforced concrete slab). Sand is used as the working layer of the road bed.

The total thickness of the pavement, taking into account the approaching reinforced concrete slabs, varied from $41 \mathrm{~cm}$ to $65 \mathrm{~cm}$ depending on the object of the survey.

As a result of the performed instrumental measurements, the presence of unfilled space (voidness) between the approaching slabs and the sandy base was recorded at all the objects examined. The results of measurements are presented in Table. 1.

Table 1. Results of measuring the thickness of dense pavement layers.

\begin{tabular}{|c|c|c|c|}
\hline Bridge structure & $\begin{array}{c}\text { Core sample } \\
\text { thickness, cm }\end{array}$ & $\begin{array}{c}\text { Depth of drilling (to the } \\
\text { base), cm }\end{array}$ & $\begin{array}{c}\text { Amount of unfilled soil } \\
\text { space (voidness), cm }\end{array}$ \\
\hline №1 & 65 & 89 & 24 \\
\hline №2 & 41 & 44 & 3 \\
\hline №3 & 53 & 61 & 8 \\
\hline №4 & 54 & 60 & 6 \\
\hline №5 & 49 & 54 & 5 \\
\hline
\end{tabular}

After driving the pavement to the sandy base, manual drilling of the working layer of the roadbed was performed to a depth of $4.5 \mathrm{~m}$ with sampling of the disturbed structure every first meter. 
Then, in laboratory conditions, the granulometric composition of the selected soil samples was determined in accordance with the applicable regulatory documents. According to the results of the determination of the particle size distribution, the selected soil samples can be classified as medium-sized sand, which is a draining, non-obese, and non-swellable soil suitable for use in construction, including the construction of suitable embankments to bridges.

According to direct measurements, the size of the voids under the approaching slabs ranges from 3 to $24 \mathrm{~cm}$. The cause of the occurrence of this defect is most likely the additional consolidation of sand, which the body of the approaching embankment consists of, over time under the action of its own weight.

The resulting subsidence of soil changes the design model of the approaching slab, which leads to its deflection and the formation of local pavement subsidence at the entry (exit) sections of bridges (from bridges) (Fig. 9).

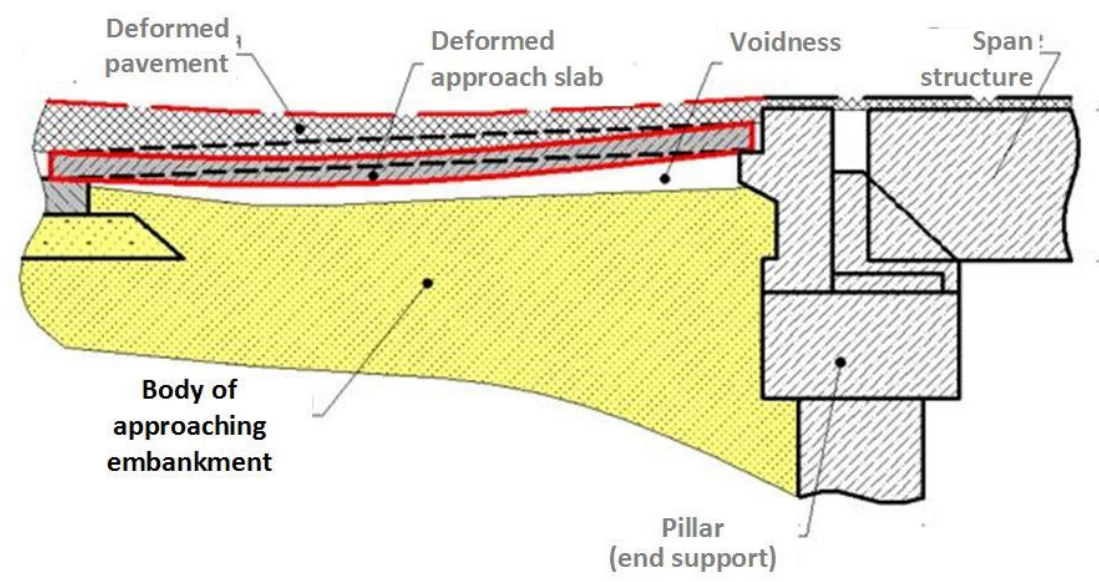

Fig. 9. Deflection deformation scheme of approaching slab.

In general, according to the results of an engineering survey of transition areas, the necessary baseline data were obtained for the development of a technical solution to eliminate and prevent the further progress of deformations.

\section{Development of a technical solution to eliminate the causes and effects of deformation of approaching slabs}

According to the results of an engineering survey, a method has been proposed for eliminating the deflection deformation of approaching slabs without dismantling existing structures, based on the injection method of filling voids and fixing soils [9]. At the same time ensuring the evenness on the site is performed by milling the coating with the laying of the leveling layer.

The elimination of decompressed zones under the approaching slabs and the filling of voids is performed by a combined method using two types of injections.

Type 1. Injection of ground-cement mortar (pressure injection), performed in the space between the approaching slabs and the unfrozen soil of the approaching embankment;

Type 2. Injections of sodium silicate with pre-activation with carbon dioxide (gas silicatization according to the "gas-glass-gas" scheme), carried out in decomposed soils of the approaching embankment. 
A generalized scheme for filling voids and strengthening the soil under the approaching slabs for the five bridges is shown in Fig. 10.

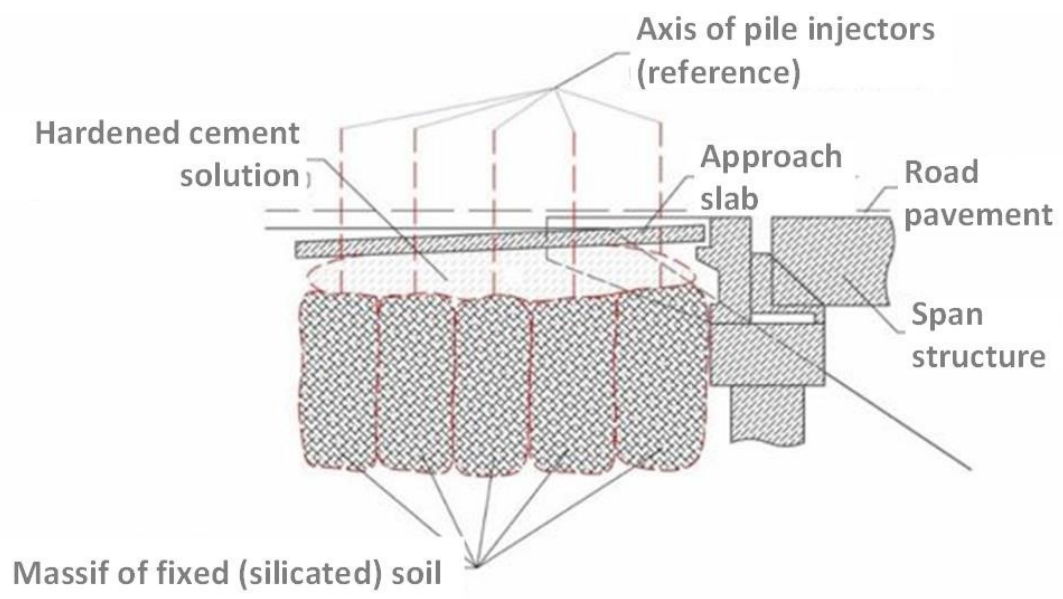

Fig. 10. Generalized scheme for filling voids and strengthening the soil under the approaching slabs.

The advantages of this variant of eliminating the causes of deformations of approaching slabs, as compared with the traditional approach - disassembling of existing structures with reorganization of the working layer of the subgrade, are:

- there is no need for a long-term restriction of traffic along the lanes of the federal highway;

- exclusion of the possibility of poor re-compaction of the soil of the working layer in cramped conditions;

- formation of arrays of silicified soil, which perceive dynamic operating load and reduce the transfer of horizontal forces to the abutments of the bridge.

When reinforcing the subgrade soil by injection, it is necessary to perform additional calculations related to the determination of injection parameters in order to prevent the discharge of the injected solution out of the reinforcement area [10].

\section{Conclusion}

Based on the conducted research, it was established that subsidence of road pavement at the interfaces between artificial structures and approaching embankments not only leads to a decrease in such consumer properties of the highway as speed, safety and driving comfort, but also contributes to the development of additional dynamic traffic effects on road structures. By the example of specific objects, it has been established that during operation, the supports of bridges are affected by effects that give them additional acceleration, reaching $1.8 \mathrm{~m} / \mathrm{s}^{2}$.

Conducted detailed survey of the interfaces of bridges with approaching embankments on the existing section of the federal highway of public importance allowed us to identify voids under the approaching slabs of 3 to 24 centimeters. The reason for the occurrence of such a defect is most likely to be the consolidation of the sand that makes up the body of the approaching embankment, over time under the action of its own weight. The resulting subsidence of soil changes the design model of the approaching slab, which leads to its deflection and the formation of local subsidence pavement. 
A method of eliminating the causes and effects of deflection of approaching slabs without disassembling existing structures, based on the injection method of filling voids and fixing soils, ensuring evenness on the site by milling the coating with the laying of the leveling layer.

\section{References}

1. A.L. Lanis, D.A. Razuvayev, P.O. Lomov, Conjugation of approaching embankments with bridges and overpasses. Scie. peer-reviewed j. "SibADI Bulletin" 2(48), 110-120 (2016)

2. L.M. Bobylev, M.M. Zhuravlev, Compaction of soil and rubble in the places where the roadbed mates with bridges and pipes. Roads 1, 16-17 (1974)

3. A.L. Lanis, D.A. Razuvaev, Corridors in the Cold and Arid Regions. Scie. in the Cold Reg. and Arid Reg. 9 (3), 205-212 (2017)

4. L.N. Stepanova, S.I. Kabanov, S.A. Bekher, M.S. Nikitenko, Microproc. Multi-chan. Strain-Gauge Syst. for Dyn. Surv. and Automat. Cont. 5, 891-897 (2013)

5. L.N. Stepanova, E.Yu .Lebedev, S.I. Kabanov, V.I. Kozhemyakin, A.E. El'tsov, N.G. Metelkin, Microprocessor multichannel tensometric system for construction testing. Defektoskopiya 4, 82-89 (2001)

6. A.N. Ser'eznov, L.N. Stepanova, V.L. Kozhemyakin, E.Yu. Lebedev Microprocessor multi-module tensometric system. Defektoskopiya 1, 82-87 (2004)

7. S.B. Teodorovich, S.M. Kulakov, V.V. Murav'ev, Active Systems. Steel in Translation 31(2), 74-79 (2001)

8. A. Kolomeets, Title Conf. Ser., 671, Issue 1, 012029, (2016)

9. A.L. Lanis, Ways to enhance the subgrade by injection. Izvestia Transsib. 3(27), $117-$ 124 (2016)

10. A. Lanis, Results of modeling the behavior of the subgrade with pressure injection of solidifying solutions. In: MATEC Web of Conf. Sib. Transp. Forum - TransSiberia, 239, 05006 (2018) DOI: https://doi.org/10.1051/matecconf/201823905006

11. M.M. Zhuravlev, Conjugation of the roadway of highway bridges with an embankment. Transport, Moscow (1976) 